\title{
Orientation of 2,6-Dicarbethoxy-3,5-bis(pyridine-3- yl)tetrahydro-1,4-thiazine-1,1-dioxide on Silver Nanoparticles: Surface-Enhanced Raman Spectral Studies
}

\author{
M. Anuratha, ${ }^{1}$ A. Jawahar, ${ }^{2}$ M. Umadevi, ${ }^{3}$ N. Edayadulla, ${ }^{4}$ V. G. Sathe, ${ }^{5}$ \\ V. Meenakumari, ${ }^{6}$ and A. Milton Franklin Benial ${ }^{6}$ \\ ${ }^{1}$ Department of Chemistry, Thamirabharani Engineering College, Thatchanallur, Tirunelveli, Tamil Nadu 627358, India \\ ${ }^{2}$ Department of Chemistry, N.M.S.S. V.N. College, Madurai, Tamil Nadu 625 019, India \\ ${ }^{3}$ Department of Physics, Mother Teresa Women's University, Kodaikanal, Tamil Nadu 624101, India \\ ${ }^{4}$ Department of Chemistry, Mother Teresa Women's University, Kodaiakanal, Tamil Nadu 624101, India \\ ${ }^{5}$ UGC-DAE Consortium for Scientific Research, University Campus, Khandwa Road, Indore 452 017, India \\ ${ }^{6}$ Department of Physics, N.M.S.S.V.N. College, Nagamalai, Madurai, Tamil Nadu 625 019, India
}

Correspondence should be addressed to A. Milton Franklin Benial; miltonfranklin@yahoo.com

Received 22 October 2013; Accepted 13 December 2013; Published 6 February 2014

Academic Editor: Jin Zhang

Copyright (C) 2014 M. Anuratha et al. This is an open access article distributed under the Creative Commons Attribution License, which permits unrestricted use, distribution, and reproduction in any medium, provided the original work is properly cited.

Silver nanoparticles were synthesized using solution combustion method with citric acid as fuel. The prepared silver nanoparticles exhibit fcc crystalline structure with particle size of $\sim 50 \mathrm{~nm}$. The morphology and purity of the silver nanoparticles were also studied by high-resolution transmission electron microscopy (HRTEM) and energy dispersive X-ray analysis (EDX). Surface-enhanced Raman scattering (SERS) spectra of 2,6-dicarbethoxy-3,5-bis(pyridine-3-yl)tetrahydro-1,4-thiazine-1,1-dioxide (DBTD) adsorbed on silver nanoparticles were investigated. Orientation of DBTD on silver nanoparticles has been inferred from normal Raman spectrum (nRs) and SERS spectral feature. The observed spectral feature evidenced that DBTD would adsorb on silver surface with tilted orientation through the lone pair electrons of $\mathrm{C}-\mathrm{N}, \mathrm{C}=\mathrm{O}, \mathrm{S}=\mathrm{O}$, and pyridine ring. The present investigation has been a model system to deduce the interaction of drugs with DNA.

\section{Introduction}

Surface-Enhanced Raman spectroscopy (SERS) is a Raman spectroscopic (RS) technique that provides enhanced Raman signal from Raman-active molecules that have been adsorbed onto certain specially prepared metal surfaces. Increases in the intensity of Raman signal have been regularly observed in the order of $10^{4}-10^{6}$ and can be as high as $10^{8}$ and $10^{14}$ for some systems $[1,2]$. The discovery of such an enormous enhancement in the Raman intensity when a molecule is in the vicinity of metal nanoparticles, coupled with the suppression of fluorescence, generated considerable excitement and suggested the possibility that SERS could provide an invaluable tool as a reliable, high-resolution detection technique for extremely minute quantities of target molecules [3].
SERS selectivity of surface signal results from the presence of surface-enhancement mechanisms only at the surface. SERS completely overcomes the disadvantage of the small cross-section of Raman spectroscopy and could be used to study the single molecule spectroscopy [4]. The structural and molecular identification power of RS can be used for numerous interfacial systems, including electrochemical, modeled, and actual biological systems; catalytic, in situ, and ambient analyses, and other adsorbate-surface interactions $[1,5]$. Due to the sensitivity of SERS, detection of trace molecules can be made [6]. SERS is observed primarily for analytes adsorbed onto coinage or alkali metal surfaces, with the excitation wavelength near or in the visible region [7]. The symmetry of a molecule can be changed in different ways depending on the orientation in which the molecule is 
attached to the surface. In some experiments, it is possible to determine the orientation of adsorption to the surface from the SERS spectrum, as different modes will be present depending on how the symmetry is modified [8]. It is highly desirable to apply in situ SERS to obtain molecular level information about the breaking and formation of bonds in the reaction, observe the reaction intermediate on the surface, and finally distinguish the reaction products [9].

Heterocycles containing nitrogen and sulfur possess important biological activities. Thiazines are six-membered heterocycle containing one sulfur atom and one nitrogen atom. A number of isomeric structures are possible depending upon the relative positions of the two hetero atoms and the degree of oxidation of the ring system. Thiazines display many important biological activities such as antitussive [10], anesthetic [11], antiradiation [12], anticonvulsant [13], sedative [14], anticoagulant [15], neuroleptic [16], and herbicide antidote [17]. They have been used as cardiovascular agents [15], antihypertensive [16], antiviral [17], anti-HIV [18], antifungal [19], anti-inflammatory [19], anthelmintic [19], and antipsoriatic [20]. The thiazine derivatives should be subjected to close scrutiny for biological action. In recent times, the cephalosporins have been used as antibiotics of great value. These mould metabolites, which contain a fused $\beta$-lactam-dihydro-1,3-thiazine skeleton, are obviously related to the penicillins and their discovery has initiated a major study which is still in progress to optimize their therapeutic effects. Earlier, tetrahydro-1,4-thiazine-1-oxide-3-carboxylic acid was isolated from algae, and recently, tetrahydro1,4-thiazine-3,5-dicarboxylic acid has been detected in the bovine brain and human urine $[21,22]$.

The adsorption of biomolecules on metal substrates has been a subject of great interest for researchers due to its broad potential applications. SERS has become a valuable tool for monitoring the changes in the chemical nature of the molecule adsorbed on metal surface. In this work, the effect of silver nanoparticles on the enhancement of SERS spectra and orientation of DBTD on the prepared silver nanoparticles was investigated. The present investigation has been a model system to deduce the interaction of drugs with DNA.

\section{Experimental}

2.1. Reagents. Silver nitrate, citric acid, diethyl $2,2^{\prime}$-sulfonyldiacetate, pyridine- 3 carboxaldehyde, and ammonium acetate were obtained from Sigma Aldrich Chemical and was used without further purifications. All glasswares were properly washed with distilled water and dried in hot air oven before use.

2.2. Preparation of Silver Nanoparticles. Stoichiometric amount of silver nitrate (1.6987 g) was dissolved in deionised water $(10 \mathrm{~mL})$ and then citric acid $(0.277 \mathrm{~g})$ was added into it. The solution was kept in the furnace at $300^{\circ} \mathrm{C}$. With large amount of fumes, the combustion reaction was completed in 15 mins and loose powder was formed. This was crushed and ground thoroughly.

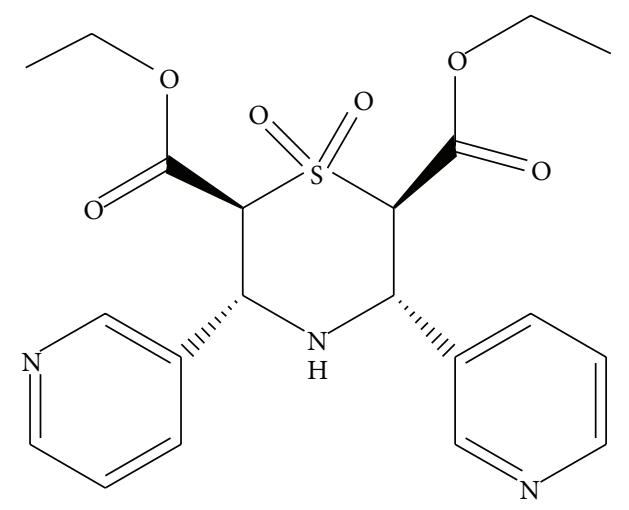

Figure 1: Structure of 2,6-dicarbethoxy-3,5-bis(pyridine-3yl)tetrahydro-1,4-thiazine-1,1-dioxide.

2.3. Preparation of 2,6-Dicarbethoxy-3,5-bis(pyridine-3-yl) tetrahydro-1,4-thiazine1,1-dioxide. To an alcoholic solution $(50 \mathrm{~mL})$ of diethyl $2,2^{\prime}$-sulfonyldiacetate $(0.01 \mathrm{M})$, pyridine-3 carboxyaldehyde $(0.02 \mathrm{M})$ and ammonium acetate $(0.02 \mathrm{M})$ were added and the mixture was refluxed for $2 \mathrm{hr}$. The reaction mixture was concentrated to half of its original volume and allowed to cool in an ice chest. The solid that separated was filtered, washed with ice cold aqueous ethanol, and crystallized from petroleum ether $\left(60-80^{\circ} \mathrm{C}\right)$ : chloroform (1:1). Figure 1 shows the structure of 2,6-dicarbethoxy-3,5bis(pyridine-3-yl)tetrahydro-1,4-thiazine-1,1-dioxide.

2.4. Experimental Techniques. The silver nanopowders were subjected to X-ray diffraction analysis (PANalytical X'pertPRO diffractometer system, Eindhoven, The Netherlands) and target was $\mathrm{Cu} \mathrm{K} \alpha$ with a wavelength of $1.5406 \AA$. The generator was operated at $40 \mathrm{kv}$ and with a $30 \mathrm{~mA}$ current. The scanning range was selected between $10^{\circ}$ and $100^{\circ}$. The size, composition, and atomic structure of the NPs were analyzed by high resolution transmission electron microscopy (HRTEM) and energy dispersive X-ray analysis (EDX) using a $200 \mathrm{kV}$ JEOL JEM 2100 microscope with lattice resolution of $0.14 \mathrm{~nm}$ and point-to-point resolution of $0.19 \mathrm{~nm}$. The samples were made by depositing the Ag NPs on a carbon coated $\mathrm{Cu}$ grid and the size measurements were performed manually on HRTEM images. The Raman spectra were recorded in the wavelength region $400-1100 \mathrm{~nm}$ by microRaman system (Jobin Yvon Horiba LABRAM-HR visible) using $\mathrm{He}-\mathrm{Ne}$ as excitation laser source at wavelength 632.8 $\mathrm{nm}$. Using confocal optics a lateral resolution of 1 micron and an axial resolution of 2 micron can be achieved. 600 and 1800 lines/mm gratings were used for dispersive geometry, the charge-coupled device (CCD) camera was used as the detector with the spectral resolution of $1 \mathrm{~cm}^{-1}$.

\section{Results and Discussion}

3.1. XRD and HRTEM Studies. The XRD pattern of prepared Ag nanoparticles was compared and interpreted with standard data (JCPDS ICDD 04-0783). In the XRD pattern (Figure 2), four diffraction peaks were observed at $2 \theta=38.056^{\circ}$, 


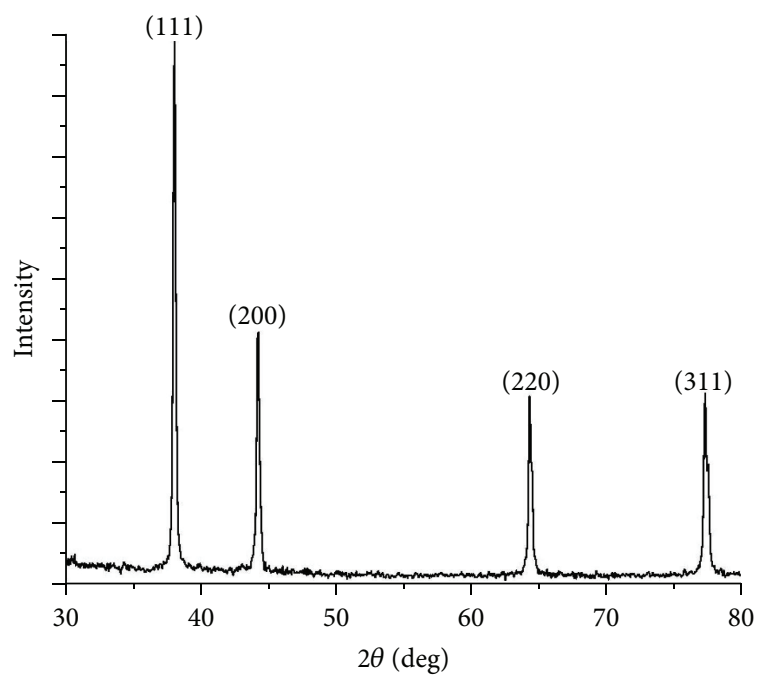

FIGURE 2: XRD pattern of silver nanoparticles.

$44.234^{\circ}, 64.389^{\circ}$, and $77.341^{\circ}$ which correspond to (111), (2 0 $0),(220)$, and (3 1 1 ) Bragg's reflections of the face centered cubic (fcc) structure of metallic silver, respectively. The peak line width in the XRD spectra is broadened due to smaller particle sizes. This XRD line width can be used to estimate the size of the particle by using the Debye-Scherrer formula as $d=0.9 \lambda / \beta \cos \theta$ where $d$ is the particle size, $\lambda$ is the wavelength of $\mathrm{X}$-ray radiation (1.5406 $\AA$ ), $\beta$ is the full width at half maximum (FWHM) of the peak (in radians) and $2 \theta$ is the Bragg angle. The calculated average particle size is found to be $\sim 50 \mathrm{~nm}$. The lattice constant values were also calculated and they agree well with the standard data. The sample exhibits smaller cell volumes than that of bulk.

HRTEM is a high-spatial-resolution structural and chemical characterization tool and provides exact information about particle size and shape. Figure 3(a) shows the HRTEM image of the preparation of the prepared silver nanoparticles. Figure 3(b) shows the energy dispersive X-ray analysis spectrum (EDX) of the prepared silver nanoparticles. It confirms the presence of elemental silver signal. The silver nanocrystallites display an optical absorption band peak at approximately $3 \mathrm{eV}$, which is due to surface plasmon resonance. The signal of $\mathrm{Cu}$ originated from the copper grid.

\subsection{SERS Studies}

3.2.1. Vibrational Assignments. Figure 4 shows the normal Raman spectrum (nRs) of DBTD. Figure 5 depicts the SERS spectrum of DBTD in silver nanoparticles. Table 1 shows the vibrational modes and its corresponding assignments.

$\mathrm{NH}$ stretching vibration generally occurs in the region $3300-3500 \mathrm{~cm}^{-1}$ [23]. The peak observed at $3275 \mathrm{~cm}^{-1}$ in $\mathrm{nRs}$ is assigned to $\mathrm{NH}$ stretching vibration. In the Raman spectrum of monosubstituted benzene, the bands which appear in the region $3000-3100 \mathrm{~cm}^{-1}$ are due to aromatic $\mathrm{CH}$ stretching vibrational mode [23]. In the present compound, the band observed at $3069 \mathrm{~cm}^{-1}$ in nRs is assigned to the $\mathrm{CH}$ stretching mode. In an aliphatic compound, the asymmetric and symmetric $\mathrm{CH}$ stretching mode of methylene group occur near 2960 and $2870 \mathrm{~cm}^{-1}$, respectively [23]. In nRs, the symmetric $\mathrm{CH}$ stretching mode observed at $2878 \mathrm{~cm}^{-1}$ is attributed to the symmetric $\mathrm{CH}$ stretching mode and the asymmetric $\mathrm{CH}$ stretching mode of methylene appeared at $2967 \mathrm{~cm}^{-1}$.

The carbonyl stretching mode falls in the region 1700$1685 \mathrm{~cm}^{-1}$ for ketones [23]. In the present case, the band observed at 1724 and $1674 \mathrm{~cm}^{-1}$ is due to $\mathrm{C}=\mathrm{O}$ stretching mode. Generally $\mathrm{C}-\mathrm{C}$ stretching mode is observed around $1602 \mathrm{~cm}^{-1}$ [23]. In the case of pyridine the $\mathrm{C}-\mathrm{C}$ and $\mathrm{C}-\mathrm{N}$ stretching modes are observed in the region $1430-1603 \mathrm{~cm}^{-1}$ [24]. In the case of phenothiazine, the ring stretching mode is observed in the region $1570-1605 \mathrm{~cm}^{-1}$ [25]. In DBTD, the modes observed in the region $1610-1420 \mathrm{~cm}^{-1}$ are assigned to $\mathrm{C}-\mathrm{C}$ stretching and $\mathrm{C}-\mathrm{N}$ stretching of pyridine. The asymmetric $\mathrm{S}=\mathrm{O}$ stretching mode of thiazine dioxide is observed at 1350 and $1368 \mathrm{~cm}^{-1}$ [26]. The asymmetric $\mathrm{SO}_{2}$ and symmetric $\mathrm{SO}_{2}$ stretching modes are observed at 1321 and $1281 \mathrm{~cm}^{-1}$, respectively [23]. In the present case, these modes are observed at 1323 and $1283 \mathrm{~cm}^{-1}$ in nRs and 1304 and $1270 \mathrm{~cm}^{-1}$ in SERS, respectively. In phenothiazine symmetric $\mathrm{Ph}-\mathrm{N}-\mathrm{Ph}$ stretching mode is observed at $1250 \mathrm{~cm}^{-1}$ [27]. In the present case the modes observed at $1225 \mathrm{~cm}^{-1}$ in $\mathrm{nRs}$ and $1254 \mathrm{~cm}^{-1}$ in SERS are due to $\mathrm{Ph}-\mathrm{N}-\mathrm{Ph}$ stretching mode. The vibrational modes occuring at 1204 and $1185 \mathrm{~cm}^{-1}$ are assigned to $\mathrm{CH}$ in-plane bending mode. The symmetric $\mathrm{S}=\mathrm{O}$ stretching mode is observed at $1130 \mathrm{~cm}^{-1}$ in $\mathrm{nRs}$ and $1140 \mathrm{~cm}^{-1}$ in SERS [26]. The vibrational mode observed at $1110 \mathrm{~cm}^{-1}$ is due to asymmetric C-N-C stretching. The bands at $1041,1030,1028,982,902$, and $901 \mathrm{~cm}^{-1}$ are due to ring breathing vibrations. In $\mathrm{nRs}$, the symmetric $\mathrm{C}-\mathrm{N}-\mathrm{C}$ stretching mode and $\mathrm{Ph}-\mathrm{S}-\mathrm{Ph}$ stretching mode are observed at 841 and $671 \mathrm{~cm}^{-1}$ respectively. In SERS, the vibrational modes observed at 860 and $877 \mathrm{~cm}^{-1}$ are assigned to symmetric $\mathrm{C}-\mathrm{N}-\mathrm{C}$ stretching mode and another mode observed at $695 \mathrm{~cm}^{-1}$ is due to $\mathrm{Ph}-\mathrm{S}-\mathrm{Ph}$ stretching mode. In SERS, the $\mathrm{CH}$ out-of-plane bending is observed at $722 \mathrm{~cm}^{-1}$. In pyridine, the in-plane ring deformation is observed at $603 \mathrm{~cm}^{-1}$ [24]. In the present case, the in-plane ring deformation modes are observed at 634 and $610 \mathrm{~cm}^{-1}$ in nRs. In SERS, the inplane ring deformation mode is observed at $591 \mathrm{~cm}^{-1}$. In the present case, OSO bending mode is observed at $526 \mathrm{~cm}^{-1}$ in $\mathrm{nRs}$ and $547 \mathrm{~cm}^{-1}$ in SERS. This mode occurs at $514 \mathrm{~cm}^{-1}$ in phenothiazine. The out-of-plane ring deformation modes are observed at 491 and $420 \mathrm{~cm}^{-1}$ in nRs and the corresponding modes appeared at 503 and $409 \mathrm{~cm}^{-1}$, respectively, in SERS.

3.2.2. Orientation Studies. There are two main mechanisms which are responsible for the observed enhancement and the shift in the SERS. One is the long range electromagnetic mechanism and the other one is the short range chemical enhancement mechanism. The electromagnetic mechanism is based on the amplification of the electromagnetic field generated due to the coupling of the radiation field with 


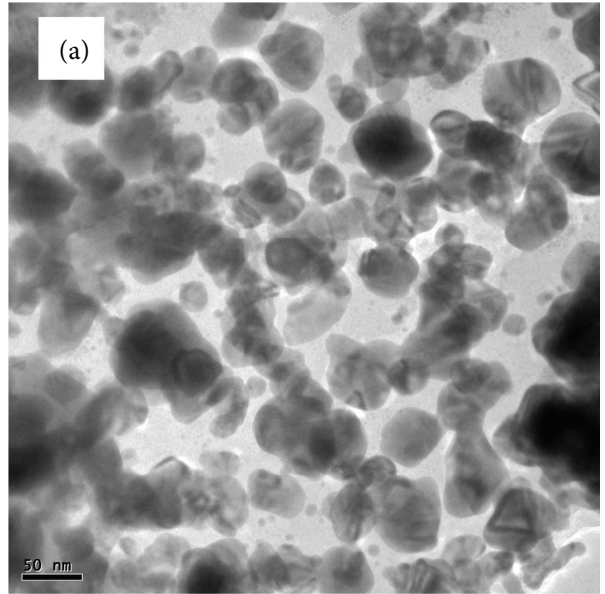

(a)

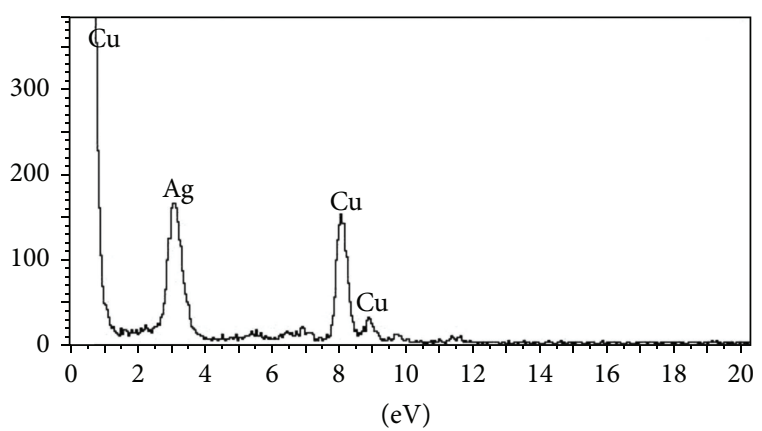

(b)

FIGURE 3: (a) HRTEM image of prepared silver nanoparticles and (b) energy dispersion spectrum of prepared silver nanoparticle.

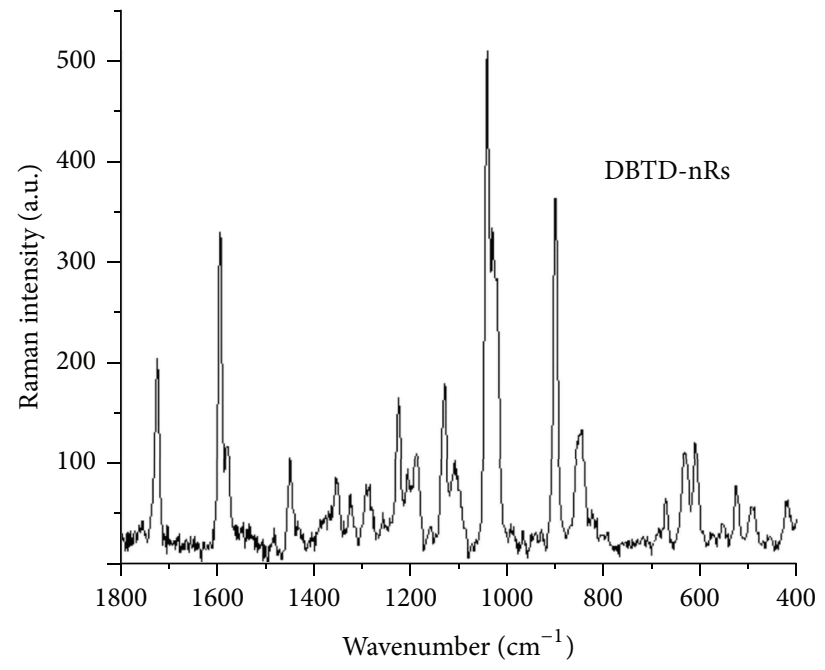

(a)

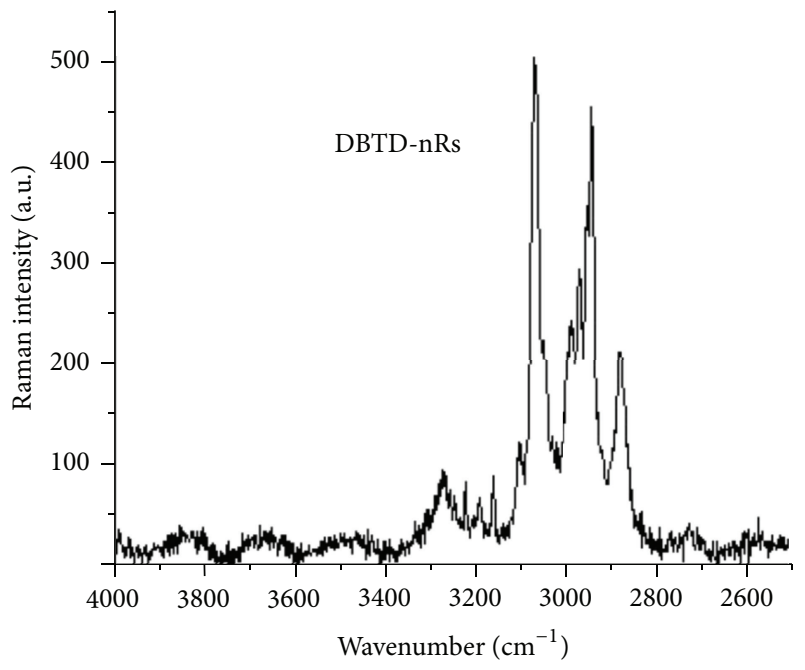

(b)

FIGURE 4: Normal Raman spectrum of 2,6-dicarbethoxy-3,5-bis(pyridine-3-yl)tetrahydro-1,4-thiazine-1,1-dioxide (DBTD) in (a) low wavenumber region and (b) high wavenumber region.

the surface plasmons of metal nanoparticles. It depends on the optical properties of the nanostructured substrate. The chemical enhancement mechanism is based on the charge transfer between the metal surface and the adsorbed molecule $[28,29]$. It may be from the HOMO of the molecule to the Fermi level of the metal or from the Fermi level of metal to the LUMO of the molecules. This mechanism depends on the chemical nature of the adsorbed molecules.

The surface-enhancement depends on the following factors. The first effect is the kind of adsorption between chemical compounds and metal NPs, that is, chemisorption or physisorption. Chemisorption shows high surfaceenhancement when compared to physisorption. The second effect depends on the orientation of the chemical compound on the metal NPs, that is, flat-on or stand-on orientation. The third effect involves the polar substitute of the chemical compound, which indicates the electron withdrawing or donating groups [30].

The orientation/adsorption mechanism of a DBTD can be deduced from its SERS spectrum through a detailed analysis of the peak shift and band broadening caused by the surface adsorption [31]. The DBTD molecule has different binding sites such as pyridine ring, lone pair electrons of oxygen, and lone pair electrons of nitrogen. There are three possible orientations that the molecule may adsorb on metal surfaces such as face-on, tilted, and stand-on orientations. The SERS effect is stronger in molecules with electron lone pairs and also in molecules with $\pi$ electron density. The orientation of the adsorbed molecule on the metal surface can be inferred from the intensity variation and shift in vibrational wavenumber of the modes in SERS with respect to the corresponding modes in nRs. 


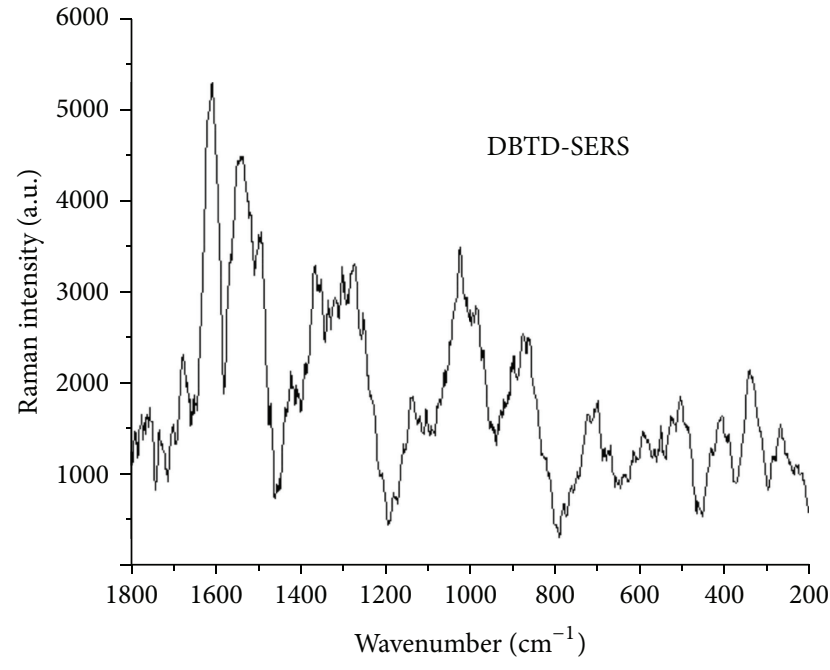

(a)

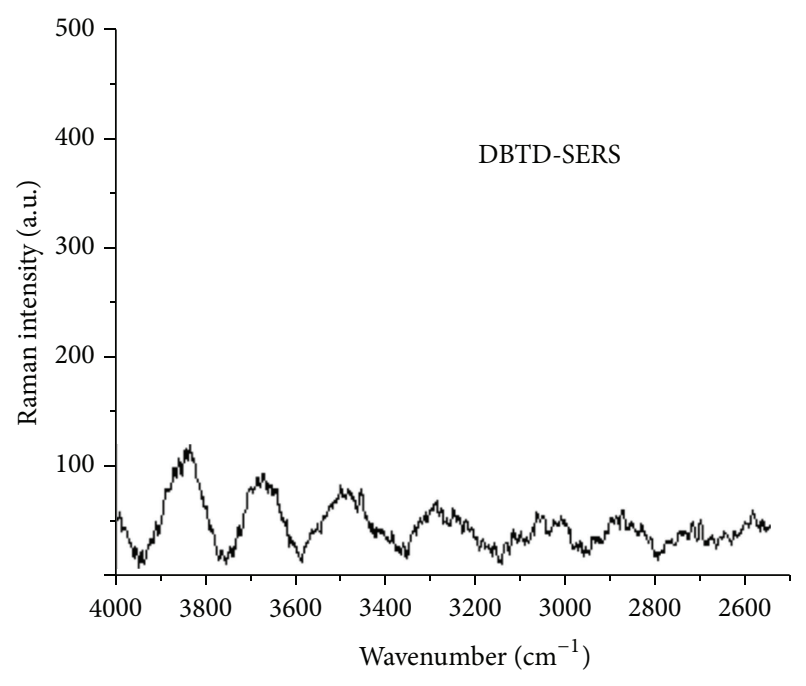

(b)

FIGURE 5: SERS spectrum of 2,6-dicarbethoxy-3,5-bis(pyridine-3-yl)tetrahydro-1,4-thiazine-1,1-dioxide (DBTD) on silver nanoparticles in (a) low wavenumber region and (b) high wavenumber region.

TABLE 1: Vibrational modes observed for DBTD and its corresponding assignments.

\begin{tabular}{|c|c|c|c|}
\hline S. no. & $\mathrm{nRs} \mathrm{cm}^{-1}$ & $\mathrm{SERS}_{\mathrm{cm}}^{-1}$ & Assignments \\
\hline 1 & 3275 & & $\mathrm{NH}$ stretching mode \\
\hline 2 & 3069 & & $\mathrm{CH}$ stretching mode \\
\hline 3 & 2967 & & Asymmetric $\mathrm{CH}$ stretching mode of methylene \\
\hline 4 & 2878 & & Symmetric $\mathrm{CH}$ stretching mode of methylene \\
\hline 5 & 1724 & 1674 & $\mathrm{C}=\mathrm{O}$ stretching \\
\hline 6 & 1591 & 1610 & $\mathrm{C}-\mathrm{C}$ and $\mathrm{C}-\mathrm{N}$ stretching \\
\hline 7 & 1577 & 1537 & $\mathrm{C}-\mathrm{C}$ and $\mathrm{C}-\mathrm{N}$ stretching \\
\hline 8 & 1449 & $\begin{array}{l}1493 \\
1425\end{array}$ & $\begin{array}{l}\mathrm{C}-\mathrm{C} \text { and } \mathrm{C}-\mathrm{N} \text { stretching } \\
\mathrm{C}-\mathrm{C} \text { and } \mathrm{C}-\mathrm{N} \text { stretching }\end{array}$ \\
\hline 9 & 1350 & 1368 & Asymmetric $\mathrm{S}=\mathrm{O}$ stretching \\
\hline 10 & 1323 & 1304 & Asymmetric $\mathrm{SO}_{2}$ stretching \\
\hline 11 & 1283 & 1270 & Symmetric $\mathrm{SO}_{2}$ stretching \\
\hline 12 & 1225 & 1254 & Symmetric $\mathrm{Ph}-\mathrm{N}-\mathrm{Ph}$ stretching \\
\hline 13 & 1204 & & $\mathrm{C}-\mathrm{H}$ in-plane bending mode \\
\hline 14 & 1185 & & $\mathrm{C}-\mathrm{H}$ in-plane bending mode \\
\hline 15 & 1130 & 1140 & Symmetric $\mathrm{S}=\mathrm{O}$ stretching \\
\hline 16 & 1110 & & Asymmetric $\mathrm{C}-\mathrm{N}-\mathrm{C}$ stretching \\
\hline 17 & 1041 & & Ring breathing \\
\hline 18 & 1030 & $\begin{array}{c}1028 \\
982\end{array}$ & $\begin{array}{l}\text { Ring breathing } \\
\text { Ring breathing }\end{array}$ \\
\hline 19 & 902 & 901 & Ring breathing \\
\hline 20 & 841 & $\begin{array}{l}860 \\
877 \\
722\end{array}$ & $\begin{array}{c}\text { Symmetric C-N-C stretching } \\
\text { Symmetric C-N-C stretching } \\
\text { CH out-of-plane bending }\end{array}$ \\
\hline 21 & 671 & 695 & Symmetric $\mathrm{Ph}-\mathrm{S}-\mathrm{Ph}$ stretching \\
\hline 22 & 634 & & In-plane ring deformation \\
\hline 23 & 610 & 591 & In-plane ring deformation \\
\hline 24 & 526 & 547 & OSO bending \\
\hline 25 & 491 & 503 & Out-of-plane ring deformation \\
\hline 26 & 420 & 409 & Out-of-plane ring deformation \\
\hline
\end{tabular}


These binding sites may lead to the adsorption of the molecule on the silver surface. The orientation of DBTD on the silver surface can be inferred from the aromatic $\mathrm{CH}$ stretching vibrations, ring stretching/breathing vibrations, in-plane and out-of-plane vibrations, and surface selection rules. According to the SERS investigation of benzene derivatives, the ring modes have to redshift by around $10 \mathrm{~cm}^{-1}$ along with an increase in their bandwidth. It shows that the surface-ring $\pi$ orbital interaction is the driving force of the surface adsorption. The red shift can be attributed to the bond weakening caused by the electron back donation from the metal to the antibonding orbital of the benzene moiety [32].

When a molecule is adsorbed flat-on the silver surface, its out-of-plane bending modes will be more enhanced compared to its in-plane bending modes according to surface selection rule and vice versa when a molecule is adsorbed perpendicular to the surface [33]. Another possible way in which the DBTD derivative stand-on adsorption occurs on the silver surface is through the $\mathrm{C}=\mathrm{O}$. The most intense signals were obtained for oxygen containing compounds bearing $\pi$ electron systems. Carboxylate and ester groups can interact strongly with metal through the formation of CT complexes between adsorbate and metal NPs where adsorbate acts like a donor and the metal like an acceptor [34]. The carbonyl oxygen makes a good binding site for surface adsorption over the metal surface. When the carbonyl groups are chelated to the metal surface, the wavenumber of the $\mathrm{C}=\mathrm{O}$ stretching mode is decreased [35]. In the present case, a single band is observed at $1719 \mathrm{~cm}^{-1}$ in nRs of DBTD due to $\mathrm{C}=\mathrm{O}$ stretching mode.

In this work, DBTD can interact with silver surface through the lone pairs of the oxygen atom of the $\mathrm{C}=\mathrm{O}$ group. According to the surface selection rule when DBTD is adsorbed on silver surface through lone pair electron of oxygen atom of the $\mathrm{C}=\mathrm{O}$ group, these modes should be appeared as prominent modes with high intensity because the polarizability tensor component is normal to the silver surface. In the present case, this prominent mode is observed at $1724 \mathrm{~cm}^{-1}$ in SERS, which indicates that the adsorption of the DBTD molecule on silver nanoparticles is through $\mathrm{C}=\mathrm{O}$ group.

Most of the bands are broadened in SERS. Generally, SERS bands of adsorbate undergo band broadening. The homogeneous and inhomogeneous contributions are responsible for the observed broadening of peaks in SERS. The homogeneous effect arises due to fundamental intramolecular interactions that will affect the lifetime and dephasing of vibrations in molecules. The inhomogeneous effect originates from the external perturbations which resulted in changes in the frequency and full width at half-maximum (FWHM) value of individual molecules. When the molecule approaches a metal surface, the electrons present in its levels undergo tunneling between the molecule and the metal. Consequently, the metal gives it a finite lifetime and hence larger FWHM [36].

Analysis of spectral line shape can provide information on vibrational dynamics, such as vibrational dephasing, which may occur by a pure dephasing and/or by energy relaxation. In pure dephasing relaxation, dynamic fluctuations of the oscillator frequency destroy the phase relationship. Energy relaxation results from the change of the oscillator phase during the energy exchange which occurs in the process of the depopulation of vibrational states. Since both the frequency fluctuations and energy relaxation are due to intraand intermolecular interactions of the oscillator with the surrounding molecules, the dephasing provides information about the dynamics of interactions and molecular motions around the oscillator [37].

The SERS spectral investigations show the prominent peaks at $1610,1537,1368$, and $1028 \mathrm{~cm}^{-1}$. The SERS bands observed at 1610 and $1537 \mathrm{~cm}^{-1}$ are shifted by 19 and $40 \mathrm{~cm}^{-1}$, respectively. The red shift may be due to the $\mathrm{C}=\mathrm{N}$ bond weakening caused by the electron back donation from metal to the antibonding $\pi$ orbital of the $\mathrm{C}=\mathrm{N}$ bond. The blue shift was explained by invoking the fact that the lone pair electrons have antibonding character and the electron donation to the silver surface may increase the strength of the $\mathrm{CN}$ bond [38].

This blue shift can be explained by considering that the interaction of the pyridine with the metal takes place via the $\pi$ electron of $\mathrm{C}=\mathrm{N}$ bond as well as the lone pair electrons of nitrogen. The blue shift can also be caused by an increase in the force constant of the corresponding vibrational mode. It may also be due to the electron charge from the molecule to the metal surface due to adsorption. The blue shift can be explained in terms of a repulsion interaction between DBTD molecules, which are present in different charge states. This may decrease the bond length and lead to blue shift [39].

The FWHM values of these modes increase due to adsorption. The observed high FWHM value may be due to the decrease in vibrational relaxation time of the DBTD on the metal surface. It also gives the evidence that the molecules (DBTD) are oriented in different form in the silver surface. The larger FWHM values reflect inhomogeneous band broadening associated with strong interactions between pyridine ring and silver surface.

The observed downshifted ring breathing mode in SERS observed at $1028 \mathrm{~cm}^{-1}$ shows that there may be weakening of the bonds in the pyridine ring system caused by $\pi$ electron donation from pyridine ring to silver surface or $\pi$ electron back donation from silver surface to pyridine ring. But the intensity of this band is decreased in SERS. Therefore the orientation of DBTD on silver surface cannot be deduced from this ring breathing vibrations. The ring stretching vibration (C-C) of DBTD is observed at 1610 and $1537 \mathrm{~cm}^{-1}$ are shifted by 19 and $40 \mathrm{~cm}^{-1}$, respectively. The band width of these bands increases. These spectral changes in ring stretching vibration indicate that the DBTD molecules adsorb on the metal surface via their $\pi$ system [32].

In the present case the in-plane and out-of-plane vibrations observed in nRs have no counterpart in SERS. Therefore the orientation determination from in-plane and out-ofplane vibrations will be neglected. The adsorption of different charge state of DBTD on silver surface may give rise to orientation effects which essentially change the symmetry of the adsorbed DBTD. As the result, the mode which is inactive in nRs becomes active in SERS, which gives rise to the bands at 
877 and $982 \mathrm{~cm}^{-1}$ in SERS due to symmetric C-N-C stretching and ring breathing mode, respectively. The intense SERS band at $1368 \mathrm{~cm}^{-1}$ is due to asymmetric $\mathrm{S}=\mathrm{O}$ stretching mode.

SERS selection rules which can be inferred from both charge transfer and electromagnetic mechanisms consider that vibrations with polarizability tensor normal to the surface suffer the highest intensity enhancement, since these vibrations imply electronic displacements which interact with the electromagnetic field produced by the surface plasmons [40]. According to this, those bands which increase in intensity give insight on the orientation of the molecule into the surface. In the present case, the DBTD molecule can be anchored on the silver surface through lone pair electron of $\mathrm{S}=\mathrm{O}$. As a result the polarizability tensor of this mode will be normal to the surface. According to the charge transfer and electromagnetic mechanism this vibrational mode gets enhanced intensity. The presence/absence of the benzene ring $\mathrm{CH}$ stretching vibration is a reliable probe for the perpendicular/parallel orientation, respectively, of the benzene ring with respect to the surface [37, 41]. In the present case, the ring $\mathrm{CH}$ stretching band is present in $\mathrm{nRs}$ which is absent in the SERS. This means that the DBTD may be adsorbed flat-on orientation on the silver surface. The observed spectral feature evidenced that DBTD would adsorb on silver surface with tilted orientation through the lone pair electrons of $\mathrm{C}-\mathrm{N}, \mathrm{S}=\mathrm{O}$, and pyridine ring.

\section{Conclusion}

The orientation of 2,6-dicarbethoxy-3,5-bis(pyridine-3-yl)tetrahydro-1,4-thiazine-1,1-dioxide (DBTD) adsorbed on silver nanoparticles was studied using SERS. Silver nanoparticles were synthesized using a solution combustion method with citric acid as fuel. The prepared silver nanoparticles have an FCC crystalline structure with the particle size of $\sim 50 \mathrm{~nm}$. The nRs and SERS spectral analysis reveals that the DBTD adsorbed tilted (neither flat-on nor stand-on) orientation on the silver surface. The morphology and purity of the silver nanoparticles were also studied by HRTEM and EDX techniques.

\section{Conflict of Interests}

The authors declare that there is no conflict of interests regarding the publication of this paper.

\section{Acknowledgments}

The authors M. Anuratha, A. Milton Franklin Benial, A. Jawahar, and V. Meenakumari thank their college management for encouragement and permission to carry out this work. One of the authors, M. Umadevi, is thankful to UGC-DAECSR, Indore, and DST-CURIE and DST-SERB, New Delhi, for financial assistance.

\section{References}

[1] K. Kneipp, H. Kneipp, I. Itzkan, R. R. Dasari, and M. S. Feld, "Ultrasensitive chemical analysis by Raman spectroscopy," Chemical Reviews, vol. 99, no. 10, pp. 2957-2975, 1999.
[2] M. Moskovits, "Surface-enhanced spectroscopy," Reviews of Modern Physics, vol. 57, no. 3, pp. 783-826, 1985.

[3] M. Fleischmann, P. J. Hendra, and A. J. McQuillan, "Raman spectra of pyridine adsorbed at a silver electrode," Chemical Physics Letters, vol. 26, no. 2, pp. 163-166, 1974.

[4] G. Xue and Y. Lu, "SERS studies of polymer surfaces and polymer/metal interfaces," Internet Journal of Vibrational Spectroscopy, vol. 4, Edititon 2, 2000.

[5] R. L. Garrell, "Surface-enhanced Raman spectroscopy," Analytical Chemistry, vol. 61, no. 6, pp. 401A-411A, 1989.

[6] A. G. Brolo, Z. Jiang, and D. E. Irish, "The orientation of $2,2^{\prime}$-bipyridine adsorbed at a SERS-active $\operatorname{Au}\left(\begin{array}{lll}1 & 1 & 1\end{array}\right)$ electrode surface," Journal of Electroanalytical Chemistry, vol. 547, no. 2, pp. 163-172, 2003.

[7] R. L. McCreery, Spectroscopy for Chemical Analysis, John Wiley \& Sons, New York, NY, USA, 2000.

[8] F. A. Parish, "Clinical evaluation of the antitussive, dimethoxanate," Medical Times, vol. 87, pp. 1488-1490, 1959.

[9] R. G. Taborsky and R. J. Starkey, "Some aspects of the chemistry of 5-ethyl-6-phenyl-meta-thiazane-," Journal of Medicinal and Pharmaceutical Chemistry, vol. 91, pp. 775-780, 1962.

[10] E. Campaigne and P. K. Nargund, "3-Alkyl-1,3-thiazane derivatives and precursors as antiradiation agents," Journal of Medicinal Chemistry, vol. 7, no. 2, pp. 132-135, 1964.

[11] S. Iwahara, T. Iwasaki, and Y. Hasegawa, "Effects of chlorpromazine and homofenazine upon a passive avoidance response in rats," Psychopharmacologia, vol. 13, no. 4, pp. 320-331, 1968.

[12] B. Narr, J. Roch, E. Mueller, W. Haarmann, and G. Offen, Chemical Abstracts, vol. 83, pp. 43369-43376, 1975.

[13] W. Oelssner Jr, G. Peinhardt, and A. Buge, "The affinity of aromatic fluoride derivatives of phenothiazine neuroleptics to spiroperidol binding sites of dopamine receptors by the radioligand technic in vitro," Pharmazie, vol. 40, pp. 341-342, 1985.

[14] W. Foery, A. Nyffeler, H. R. Gerber, and H. Martin, Chemical Abstracts, vol. 105, pp. 166904-166907, 1986.

[15] J. S. Boger, M. G. Bock, R. Freidinger et al., Chemical Abstracts, vol. 108, pp. 6427-6436, 1988.

[16] A. W. Faull, Chemical Abstracts, vol. 127, pp. 234328-234339, 1997.

[17] K. Malagu, J. Boustie, M. David et al., "Synthesis and antiviral activity of new 1,4-benzothiazines: sulphoxides and sulphone derivatives," Pharmacy and Pharmacology Communications, vol. 4, no. 1, pp. 57-60, 1998.

[18] M. Arranz, J. A. Díaz, S. T. Ingate et al., "Synthesis and anti-HIV activity of 1,1,3-trioxo-2H,4H-thieno[3,4-e][1,2,4]thiadiazines (TTDs): a new family of HIV-1 specific non-nucleoside reverse transcriptase inhibitors," Bioorganic and Medicinal Chemistry, vol. 7, no. 12, pp. 2811-2822, 1999.

[19] S. K. Srivastava, R. Yadav, and S. D. Srivastava, "Synthesis and biological activity of 4-oxothiazolidines and their 5-arylidenes," Indian Journal of Chemistry B, vol. 43, no. 2, pp. 399-405, 2004.

[20] H. Moriyama, T. Tsukida, Y. Inoue et al., "Azasugar-based MMP/ADAM inhibitors as antipsoriatic agents," Journal of Medicinal Chemistry, vol. 47, no. 8, pp. 1930-1938, 2004.

[21] R. M. Matarese, L. Pecci, and G. Ricci, "Hexahydro-1,4thiazepine-3,5-dicarboxylic acid and thiomorpholine-3,5dicarboxylic acid are present in normal human urine," Proceedings of the National Academy of Sciences of the United States of America, vol. 84, no. 15, pp. 5111-5114, 1987. 
[22] L. Pecci, M. Costa, F. Pinnen, A. Antonucci, and D. Cavallini, "Specific method for the determination of 1,4-thiomorpholine3,5-dicarboxylic acid and its unsaturated analogue lanthionine ketimine," Journal of Chromatography, vol. 426, no. 1, pp. 183$187,1988$.

[23] N. B. Colthup, L. H. Daly, and S. E. Wilberley, Introduction to Infrared and Raman Spectroscopy, Academic Press, New York, NY, USA, 1990.

[24] N. Nanbu, F. Kitamura, T. Ohsaka, and K. Tokuda, "Adsorption of pyridine on a polycrystalline gold electrode surface studied by infrared reflection absorption spectroscopy," Journal of Electroanalytical Chemistry, vol. 470, no. 2, pp. 136-143, 1999.

[25] B. Kure and M. D. Morris, "Raman spectra of phenothiazine and some pharmaceutical derivatives," Talanta, vol. 23, no. 5, pp. 398-400, 1976.

[26] N. Edayadulla and P. Ramesh, "Synthesis and physiological evaluation of new N-nitroso-2,6-dicarbethoxy-3,5diaryltetrahydro-1,4-thiazine-1,1-dioxides," Medicinal Chemistry Research, vol. 21, pp. 2056-2063, 2012.

[27] T. Iliescu, M. Baia, and I. Pavel, "Raman and SERS investigations of potassium benzylpenicillin," Journal of Raman Spectroscopy, vol. 37, no. 1-3, pp. 318-325, 2006.

[28] S. J. Lee, Z. Guan, H. Xu, and M. Moskovits, "Surface-enhanced Raman spectroscopy and nanogeometry: the plasmonic origin of SERS," Journal of Physical Chemistry C, vol. 111, no. 49, pp. 17985-17988, 2007.

[29] F. Avila, J. Soto, J. F. Arenas, J. A. Rodríguez, D. Peláez, and J. C. Otero, "Outstanding role of silver nanoparticles in the surfaceenhanced resonance raman scattering of p-benzosemiquinone," Journal of Physical Chemistry C, vol. 113, no. 1, pp. 105-108, 2009.

[30] N. Goutev and M. Futamata, "Attenuated total reflection surface-enhanced infrared absorption spectroscopy of carboxyl terminated self-assembled monolayers on gold," Applied Spectroscopy, vol. 57, no. 5, pp. 506-513, 2003.

[31] A. G. Mal'shukov, "Surface-enhanced raman scattering. The present status," Physics Report, vol. 194, no. 5-6, pp. 343-349, 1990.

[32] P. Gao and M. J. Weaver, "Surface-enhanced Raman spectroscopy as a probe of adsorbate-surface bonding: benzene and monosubstituted benzenes adsorbed at gold electrodes," Journal of Physical Chemistry, vol. 89, no. 23, pp. 5040-5046, 1985.

[33] X. Gao, "A test of surface selection rules for surface-enhanced raman scattering: the orientation of adsorbed benzene and monosubstituted benzenes on gold," Journal of Physical Chemistry, vol. 94, no. 17, pp. 6858-6864, 1990.

[34] L. Guerrini, Z. Jurasekova, C. Domingo et al., "Importance of metal-adsorbate interactions for the surface-enhanced raman scattering of molecules adsorbed on plasmonic nanoparticles," Plasmonics, vol. 2, no. 3, pp. 147-156, 2007.

[35] G. Smulevich and A. Feis, "Surface-enhanced resonance Raman spectra of adriamycin, 11-deoxycarminomycin, their model chromophores, and their complexes with DNA," Journal of Physical Chemistry, vol. 90, no. 23, pp. 6388-6392, 1986.

[36] B. N. J. Persson and R. Ryberg, "Vibrational interaction between molecules adsorbed on a metal surface: the dipole-dipole interaction," Physical Review B, vol. 24, no. 12, pp. 6954-6970, 1981.

[37] K. S. Schweizer and D. Chandler, "Vibrational dephasing and frequency shifts of polyatomic molecules in solution," The Journal of Chemical Physics, vol. 76, no. 5, pp. 2296-2314, 1982.
[38] H. S. Han, S. W. Han, S. W. Joo, and K. Kim, "Adsorption of 1,4phenylene diisocyanide on silver investigated by infrared and Raman spectroscopy," Langmuir, vol. 15, no. 20, pp. 6868-6874, 1999.

[39] A. K. Ojha, "pH dependent SERS and solvation studies of tyrosine adsorbed on silver colloidal nano particles combined with DFT calculations," Chemical Physics, vol. 340, no. 1-3, pp. 69-78, 2007.

[40] J. A. Creighton, "The selection rules for surface-enhanced Raman spectroscopy," in Spectroscopy of Surfaces, R. J. H. Clark and R. E. Haster, Eds., Wiley, Chichester, UK, 1988.

[41] J. S. Suh and M. Moskovits, "Surface-enhanced Raman spectroscopy of amino acids and nucleotide bases adsorbed on silver," Journal of the American Chemical Society, vol. 108, no. 16, pp. 4711-4718, 1986. 

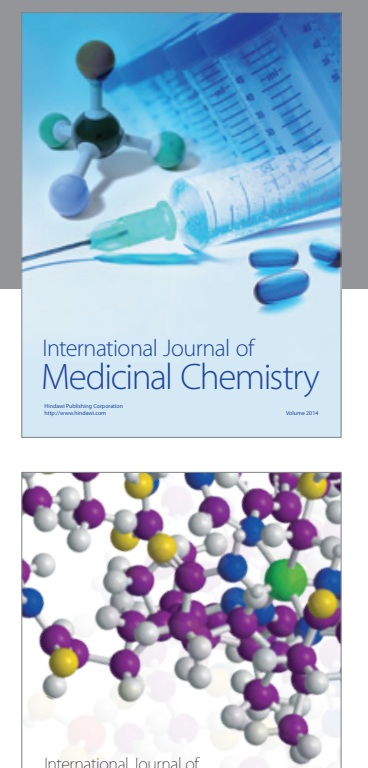

\section{Carbohydrate} Chemistry

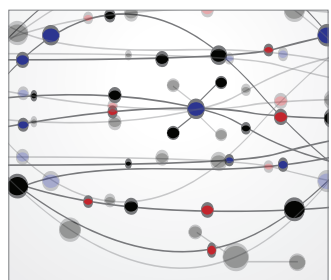

The Scientific World Journal
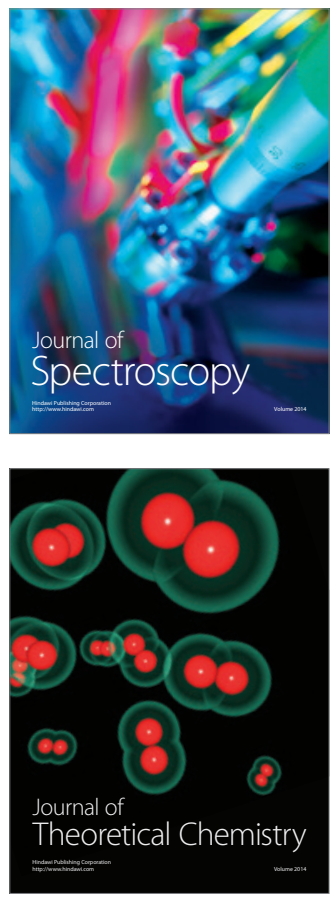
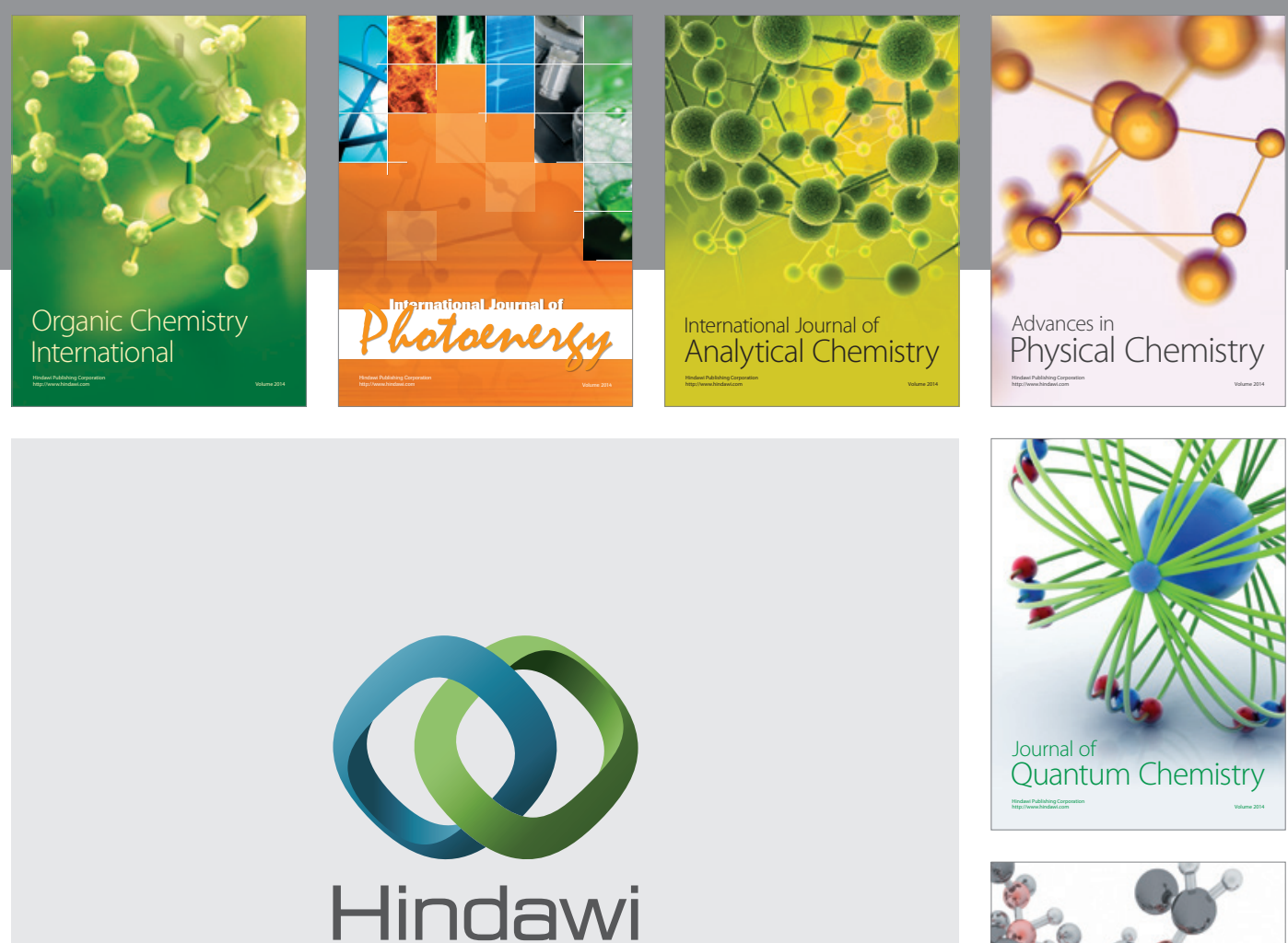

Submit your manuscripts at

http://www.hindawi.com

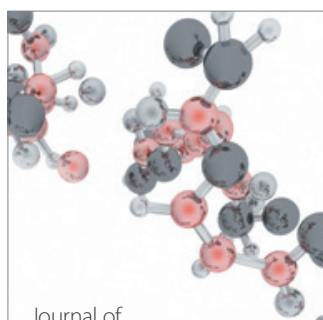

Analytical Methods

in Chemistry

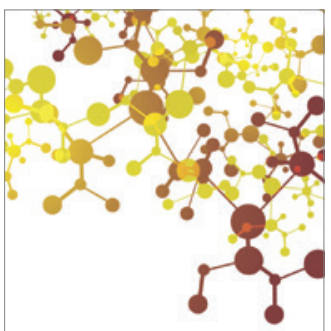

Journal of

Applied Chemistry

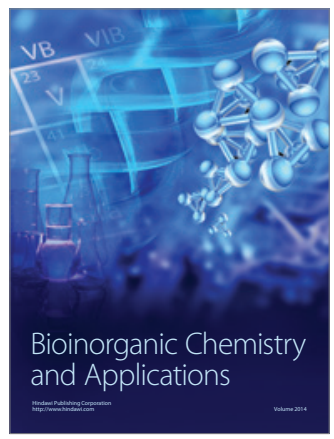

Inorganic Chemistry
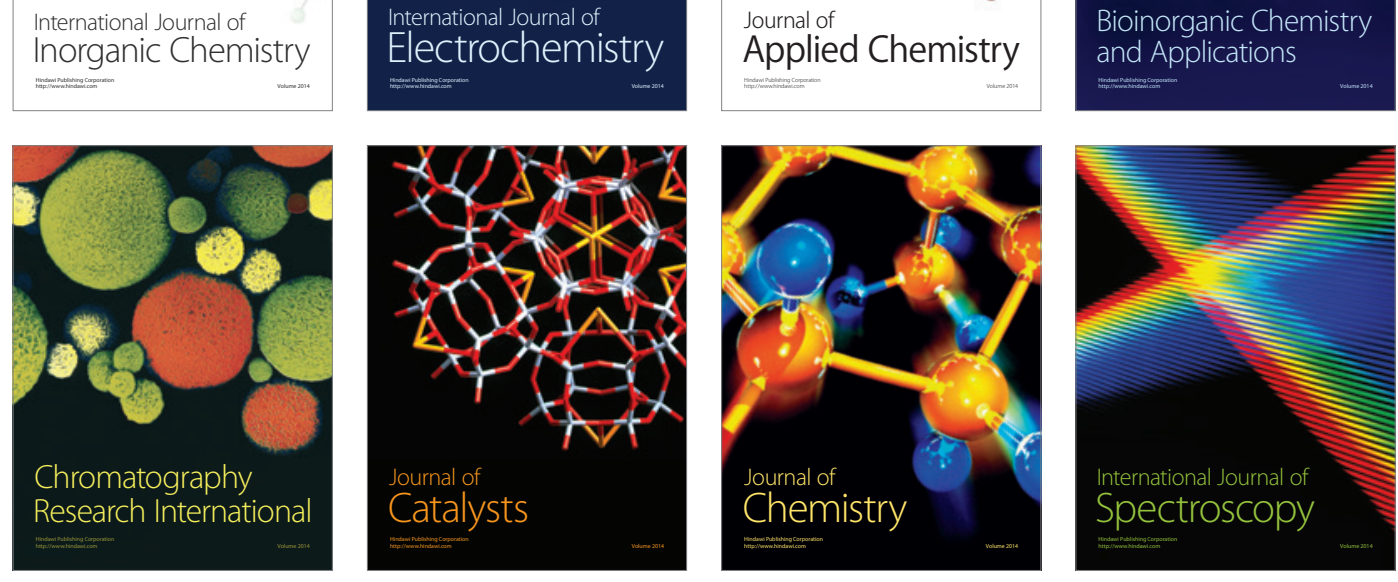